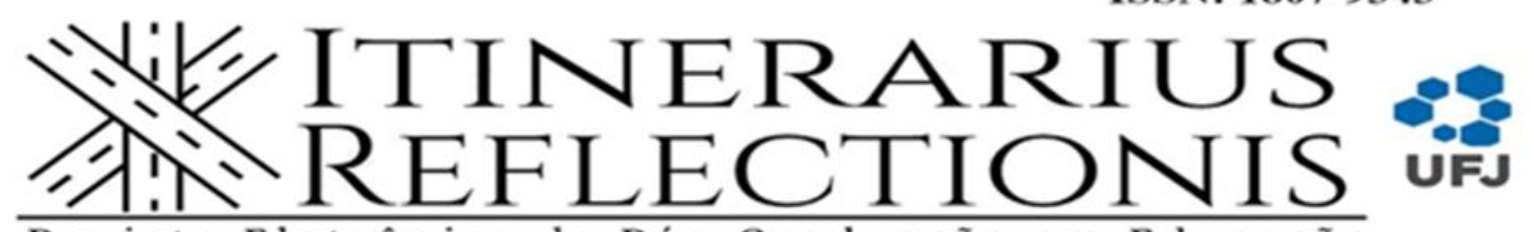

Revista Eletrônica da Pós-Graduação em Educação

Universidade Federal de Jataí

Volume, 17, n.4, ano 2021

\title{
O ensino de filosofia na educação das crianças: perfil político pedagógico
}

\author{
Beatriz Silveira de Paula ${ }^{1}$ \\ Edson de Sousa Brito \\ José Silvio de Oliveira ${ }^{3}$
}

\begin{abstract}
RESUMO Compreender a natureza, isto é, o sentido da filosofia educativa para crianças como meio formativo, político e intelectual é a meta desse ensaio. O atual problema na ausência dos conteúdos filosóficos essenciais, sobretudo, no ensino público infantil brasileiro, sem dúvida, inibe e limita, o estímulo ao pensamento, aos questionamentos da própria formação da educação infantil. A metodologia aplicada possui caráter exploratório, qualitativo, bibliográfico. $\mathrm{O}$ artigo divide-se em três partes sistematizadas: a) a compreensão sobre a filosofia pedagógica e poder político estatal; b) a filosofia educativa, escola, vida infantil e, finalmente, c) o Estatuto da Criança e do Adolescente como marco legal constituinte fundamental ao exercício dos direitos infantis. As referências adotadas são: Coêlho (2001), Lipmann (2001), Lima (2018). A instabilidade democrática instaurada, reforça necessidade à luta coletiva política, em movimentos antirracistas, antifascistas, especialmente, ao feminismo, afim de reformas socioculturais a revolução. Manutenção da liberdade e, felicidade está/é sob controle governamental no espaço onde a tecnologia regula o poder da verdade; a arte da filosofia, em diversas formas de representação, simboliza sentimento da esperança, no espaço de ignorância. Romper com as questões contrárias à filosofia do aspecto infanto-juvenil no mundo pós-moderno é, tarefa universal impreterível na sociedade, cultura, educação, em instituições da educação infantil.
\end{abstract}

Palavras-chave: Ensino, Filosofia Infantil, Política.

ABSTRACT Understanding naturre, that is, the meaning of educational philosophy for children as a formative, political and intelectual means is the aim of this essay. The current problem in the absence of essential philosophical content,especially in public childhood education in Brazil, undoubtedly inhibits and limits the stimulus to thought, to the questioning of the very formation of Early childhood education. The methodology has an exploratory, qualitative and bibliographic caracter. The article is divided into three systematized parts: a)

\footnotetext{
${ }^{1}$ Graduanda em Pedagogia pela Universidade Federal de Jataí. E-mail: beatriz_depaula@outlook.com.br

2 Doutor em Educação (PUC-GO). Professor Ajunto I da Universidade Federal de Jataí. Possui graduação em Filosofia pela Pontifícia Universidade Católica de Goiás, mestrado em Filosofia pela Universidade Federal de Goiás. Foi membro da comissão assessora de área do Instituto Nacional de Estudos e Pesquisas Educacionais Anísio Teixeira (INEP), professor pesquisador da Universidade Federal de Jataí. Coordenador do grupo de pesquisa Educação e filosofia política: estudos em Jean-Jacques Rousseau. Professor da área de Fundamentos da educação, atuando nas disciplinas de Filosofia da Educação, Filosofia e Corporeidade e Filosofia da Ciência. Email: edsonbrito@ufj.edu.br
}

\footnotetext{
${ }^{3}$ Doutor em Educação e docente do Curso de Pedagogia da UAE/EDU da Universidade Federal de Jataí/UFJ, email: js89083@ufj.edu.br
} 
understanding of the pedagogical philosophy and state political power; b) the educational philosophy, school, children's life and, finally, c) the Child and Adolescent Statute as a fundamental legal framework for the exercise of children's rights. The adopted references are: Coêlho (2001), Lipmann (2001), Lima (2018). The estabished democratic instability reinforces the need collective political struggle, in anti-racist and anti-fascist movements, especially feminism, in order to sociocultural reforms and the revolution. Maintaining freedom and happiness is/is under government control in the space where technology regulates the power of truth; the art of philosophy, in the various forms of representation, symbolizes the feeling of hope, in the space of ignorance. Breaking with issues contrary to the philosophy of the child-juvenile aspect in the past-modern world is a universal task that is imperative in society, culture, education, in early childhood education institutions.

Keywords: Teaching, Children's Philosophy, Politics.

\section{INTRODUÇÃO}

Este artigo objetiva compreender o sentido da filosofia para educação no âmbito infantil, sobretudo, na perspectiva escolar, tendo como parâmetro de reflexão, o contexto político das sociedades moderno-contemporânea. Neste sentido, a delimitação do tema para o ensaio, em certo sentido, envolve o estudo da prática pedagógica filosófica infantil que, aborda sobre educação progressista no modelo apto para conteúdos transversais. Nas tentativas governamentais de silenciamento, os diálogos entre educadores e, educadoras para com Estado, parece intangível às tentativas das implementações de efetivas políticas públicas brasileiras. Projetos de Leis como 'Escola Sem Partido', são resultados das armadilhas sistêmicas estatais de tapear e, fraudar as noções socias da própria verdade no uso das escolas, -professores-, como ferramentas reprodutoras da educação tecnicista neoliberal. A ausência da filosofia essencialmente, na educação básica infantil, inibe e limita o desenvolvimento à autonomia das crianças ao pensamento crítico próprio, às noções do meio sociopolítico estabelecidas sob dolorosas circunstâncias, por exemplo fome, violência, alcoolismo/drogas no âmbito familiar. $\mathrm{O}$ espaço que a filosofia da educação promove nas instituições escolares, operando em matérias/disciplinas, promove nos primeiros anos ensino-aprendizagem, conceitos, questionamentos dos valores do 'eu' e 'outro/a', fatores relacionados a construção individual de juízo, ética, moral. O ofício desafiador em lecionar para educação libertadora atua diretamente ao objeto de estudo da presente pesquisa, as crianças, onde, aqui se descreve e contempla a filosofia educativa em seus amplos aspectos formativos pedagógicos técnicos, a possibilidade do ensino filosófico em aulas, o debate aos temas de interesse social: respeito, 
ações da cidadania, o espaço de fala, posicionamento/luta política para equidade, direitos infantis, importância da permanência de crianças na instituição escolar como garantia a formação intelectual e manutenção das condições sociais. O suposto discurso midiático da meritocracia e poder evidencia as injustiças, incertezas, falhas governamentais na ordem, no devido mal funcionamento do exercício de responsabilidades/garantias políticas a nação para direitos básicos em sociedade, o trabalho, serviços empregatícios com adequada remuneração, valorização aos profissionais, aposentadoria, educação pública.

As escolas, mesmo como sistema hierarquizado, submisso às normas de silenciamento propostas pelo governo, possibilita, entretanto, no espaço de transformação, que crianças pela prática pedagógica, atribuam relevância ao questionamento e indagações, a busca da essência do ser, a inquietação para investigação dos comportamentos sociais. A mediação docente na construção da identidade infantil escolar se desloca para ação civil, ou seja, pela atuação política do oficio de lecionar em viabilizar às crianças ferramentas pelo uso da linguagem, o alcance da verdade própria, na pedagogia de libertação, como perspectiva de direção filosófica aos questionamentos da existência humana. A formulação da identidade, fuga do comodismo, as noções de privilégios, ocasionam novos sentidos de compreensão à natureza individual. Conquistas, mudanças históricas, guerras e revoluções, provém de ações coletivas, a filosofia enquanto ferramenta, dispõe artifícios para que o pensamento se combine à arte em suas diferentes linguagens e segmentos, a fim de exaltar cultura, viabilizar a socialização, legitimar democracia.

Para atingir os objetivos propostos nesse artigo, as leituras, análises, estudos de autores/autoras foram indispensáveis na construção deste trabalho, a filosofia como fonte de conhecimento para nova perspectiva de educação pedagógica, usufrui de conteúdos transversais, concede a quem aprimora da instrução filosófica a fuga da alienação, consciência de classe, responsabilidade na luta pela igualdade, quebra de paradigmas, desconstrução de conceitos, aproximação real do discurso com ação. O caminho à razão, ao conhecimento próximo do dito verdadeiro, se dá no processo de reconhecimento da própria ignorância, o princípio da dúvida e, crítica/julgamento as imposições sociais exigidas. A disseminação das ideologias autoritárias, fascistas, de extrema direita, arrisca a liberdade de expressão, ameaça os direitos humanos, propaga ódio e traça contrário caminho a fala/contribuição filosófica. $\mathrm{O}$ Estado que toma do povo o que lhes é de direito, retribui com migalhas, exige enaltecimentos, ocupa-se com incansáveis ganâncias enquanto pobres são ignorados e esquecidos pelo sistema, não desfrutam do mínimo como saneamento básico. A desigualdade aumenta e o 
glamour dos engravatados é encobertado pela massa de manobra, enganada pelo falatório popular, vendem-se às armadilhas políticas.

A ausência do diálogo entre governo e educandos, educandas, enfraquece a autonomia docente em sala de aula, reforça a escola como instrumento de dominação e alienação do Estado onde, justifica-se erroneamente, que profissionais do campo da educação estariam impondo ideais com viés partidários ideológicos nas instituições, por consequência, assuntos políticos permanecem como tabu, professores e professoras são silenciados/as, a eminente ditadura é imposta de forma disfarçada por democracia, Constituição da República Federativa do Brasil é afrontada, ferida, onde, estabelece-se o golpe na história do país. O que soa como ciclo vicioso entre conquistas e derrotas, ganho e perca dos direitos, a sociedade civil polariza-se pelo senso comum e, no discernimento prudente, criterioso, de equilíbrio e, lucidez.

A ditadura da censura, silenciamento, alimenta juiz de valor que, prevalece e torna-se mais presente no cotidiano. A revolução distancia-se à medida que a classe operante não se mobiliza às lutas e, é tomada pela onda soberba regida pelas autoridades administrativas. Os mitos, isto é, algo inventado para que seja verdade, é vendido pelos ricos, empresários, governantes, uma vez que são mecanismos de contenção popular à luta e revolução. Compreender filosofia em seu sentido é, contudo, interrogar seu significado e sua origem educativa. A filosofia por si, cumpre o papel de educar, orientar e questionar. O tema educação e filosofia para esta pesquisa é sem dúvida escolher a razão formativa do ser humano. Pensar a filosofia e educação em seu amplo contexto é ao mesmo tempo investigar a interação entre educação e cidadania. No contexto histórico e ideológico do Brasil ou das demais sociedades ocidentais onde, a formação humana, o ensino, o currículo, as teorias, práticas, didáticas, instruções, abordagens pedagógicas, nem sempre correspondem às propostas educacionais, não cumprem com sua especificidade. A desconstrução de conceitos provindos do senso comum e com o dogmatismo, torna-se mais que necessária entender o sentido da filosofia e seu efeito educativo. Do ponto de vista problemático das propostas e políticas educacionais apresentadas pelo Ministério da Educação junto às escolas brasileiras, também ao meio acadêmico, muitas vezes têm sido superficiais, reducionistas, instrumentalistas e visam em grande parte a (re)produção do que o mercado exige, à economia, em detrimento da formação humana, onde, não é propiciada a abertura ao debate, a crítica, manifestação de contradições da vida social e da escola. Portanto, é tarefa e, cabe a filosofia indagar, além disso, pensar problemáticas/inconsistências da vida cotidiana e, dar conotação aos conceitos que circundam o espaço, o horizonte da escola, sociedade, cultura, ao 
mesmo tempo, propor questionamentos que englobem as articulações/mecanismos para o exercício intelectual dos/as estudantes e professores/as. Ao pensar especificamente o objeto de pesquisa, os espaços que filosofia atua no desenvolvimento da criança é instrumento fundamental para a absorção e prática dos valores éticos, também dos deveres enquanto cidadão e cidadã. Sobre ensino filosófico para crianças, escreve Dinis a respeito do estudo realizado em relação ao Programa de Matthew Lipman:

\begin{abstract}
Esta nova abordagem pela filosofia acaba por dar a FpC uma importância capital dentro do quadro educativo, promulgando em si uma tendência especial para romper com a educação para instruir e contribuir essencialmente para uma educação para pensar. A sociedade necessita, e cada vez mais, de pessoas que amem o saber e, ao mesmo tempo, que saibam pensar, antes mais pela cada vez maior complexidade do nosso mundo e, não menos importante, por incorporar na sociedade cidadãos que saibam pensar por elas próprios e não pelas cabeças dos políticos e corporações (DINIS, 2011, p.02).
\end{abstract}

Refletir as inúmeras adversidades que vão de frente à filosofia, permite observar e entender que ela atua como objeto transformador, portanto, racionalizar fatores e as engrenagens que o sistema capitalista utiliza como massa de manobra é de fundamental importância, uma vez que, quando retiradas as matérias de filosofia e sociologia e/ou dadas como optativas, implicaria e têm marco na história brasileira o retrocesso educacional. No tocante à educação infantil, o tema deve ser tratado, abordado, de maneira adequada. Indagar, questionar, criar conceitos, são elementos iniciais para a prática pedagógica.

A formação docente deve atuar de maneira gentil, curiosa, livre, e, técnica-objetiva ao saber científico. Pela forma subjetiva, é necessária a racionalização das formas de compreensão do mundo, da existência humana. Segundo Marilena Chauí (2008), o questionamento, desde a essência da ideia de existência educativa, formula-se como proposta à política do saber formativo. As ações em meio educacional se fazem necessárias no embate ao regime capitalista, no qual, os processos em alteração ideológica atingem mudanças nas relações dominantes explorativas. Somente na emancipação aos movimentos políticos antiautoritários para propostas conscientes, é possível lograr das políticas públicas:

Um trabalho filosófico que concebe a história como história do Espírito. Este começa exteriorizando-se ou manifestando-se na produção das obras culturais (sociedade, religião, arte, política, ciência, filosofia, técnicas etc.), numa perpétua divisão consigo mesmo, isto é, a produção do Espírito são contradições que vão sendo superadas por ele e respostas com novas formas por ele mesmo. Esse trabalho espiritual prossegue produzindo novas sínteses (novas culturas), até que se produza a síntese final. Esta é produzida no momento em que o Espírito é em si (as obras culturais) torna-se o que o Espírito é para si (compreensão de sua obra como realização sua). Esse momento final chama se filosofia. [...] trabalho filosófico que pensa a história como reflexão. Reflexão significa: volta sobre si mesmo. Em geral, 
considera-se que somente a consciência é capaz dessa volta sobre si, isto é, de conhecer-se a si mesma como consciência. Só a consciência seria capaz de reflexão. Para Hegel, essa reflexão da consciência é apenas uma forma menor da verdadeira reflexão, que é a do Espírito. Este exterioriza-se em obras, mas é capaz de reconhecer-se como produtor delas, é capaz de compreender-se ou de interiorizar sua criação. (CHAUÍ, 2008, p.40-41).

O tempo é fator histórico determinante das mudanças sociais. As perspectivas pedagógicas na construção da filosofia humanista significam, posicionar-nos diante realidade, tantas vezes, trágica. (Re)conhecer a ti é retornar ao primitivo, somos animais selvagens, não de grandes/desafiadoras garras, sim, providos/as em sentimentos como compaixão, empatia, que une, preenche, a alma humana por caminhos de respeito e cidadania. Encaramos fragilidade sapiens, quando nos contextualizamos com os crescentes números dos suicídios, medicações superficiais no tratamento à saúde mental para sociedade na qual, sofre frequentemente com amparo da tristeza numa dolorosa sensação existencial do mundo. Não há como alcançar felicidade sem nos encontrarmos em nós próprios, na profunda solidão, dentro do absoluto vazio da existência.

\section{Filosofia pedagógica, sociedade, poder político estatal}

Analisar o significado da filosofia na sua profunda essência, as implicações e o impacto social dela no atual no contexto sociopolítico e cultural, a qual trata-se e opera no exercício pedagógico docente para mudanças não somente na escola, como em todo meio de vivência, sobretudo, questões abrangentes a educação infantil. Conforme Heidegger, filósofo alemão, a 'resposta filosofante' se ela for por ela mesma uma 'res-posta filosofa', e, só seria possível se apropriarmos de um diálogo, do debate, questionamento no meio sociocultural em que estamos inseridos, A filosofia funda-se na admiração, no espanto, não pelo medo, do temor ou susto, contudo, o maravilhamento da realidade, as possibilidades, necessidades existenciais que muitas vezes são ignoradas, despercebidas, desfavorecidas pelos cidadãos. $\mathrm{O}$ espanto origina-se e faz parte da filosofia, acompanha o ser no decorrer de sua vida, na operação do pensamento, da revisão de ideias sobre o ambiente e, também a sociedade. $\mathrm{O}$ caminho traçado para o alcance das ideias, à essência, a substância, à verdade, as soluções, enfim, ao sentido do próprio existente, remove-nos e desprende-nos da acomodação.

A história da filosofia aflora nas colônias gregas da Ásia Menor e da Magna Grécia, (localizada na Itália meridional), em um demorado e complexo processo de laicização e 
secularização da religião e do mito. A racionalização das diferentes formas e concepções da compreensão da realidade e da existência aflige inicialmente a natureza, ou seja, a physis ${ }^{4}$. As tarefas da filosofia desde seu princípio, priorizaram a busca de soluções fundamentadas em questionamentos que indagam as pessoas. Compreender que as respostas encontradas devem ser tratadas como prováveis e não como certezas absolutas, contribui para percepção do espaço social em que estamos inseridos/as. Portanto, o conhecimento filosófico direciona-se ao levantamento de problematizações referentes não somente à vida humana, como também de mundo e tomada de decisões.

Proporcionar situações de investigações filosóficas para a prática pedagógica reforça interesses pelas atividades escolares, impulsiona o potencial do pensamento, da atuação cidadã em conformidade à cultura individual que cada um/a encontra-se, impulsionando e contribuindo com o desenvolvimento das crianças nos anos iniciais do Ensino Fundamental.

O incentivo ao diálogo, a superação das dificuldades para assimilação do conhecimento científico sistematizado, auxílio docente ao aprimoramento do pensamento crítico, questionamentos e indagações, envolve à proposta filosófica de ensino onde oportuniza-se o exercício da compreensão e consciência pelo instrumento da filosofia. A noção individual da realidade busca do entendimento dos acontecimentos além da aparência imediata, abrange e requer visão ampliada, progressista para as percepções às problemáticas sociais. O papel significativo da filosofia e, portanto, não resolver inteiramente os problemas do mundo, e sim, servir, vestir à sociedade enquanto ferramenta transformadora, objeto de mudança para a reafirmação sobre valores éticos, à arte, ciência, política e religião.

A contestação violenta contra filosofia no atual contexto político, a retirada da disciplina dos currículos escolares, evidencia os movimentos do Estado em viabilizar fortes mudanças socioculturais e políticas. A educação na infância recupera e constrói uma nova história para a didática pedagógica nacional, partindo do pressuposto antropológico onde a visão da criança modificou-se de adulto/a em miniatura, da repressão e trabalho infantil para o/a ser verdadeiro/a, visível, competente, capacitado/a da própria história e, identidade.

As interações cotidianas, junto as mediações da criança com adultos, sobrevêm em espontaneidade na linguagem oral/gestual infantil, aprender a pensar e, compreender o mundo das ideias torna-se o principal desafio da educação. A liberdade na elaboração das certezas próprias dos conhecimentos, regras éticas, morais, enfatizam a noção de que o pensamento

\footnotetext{
${ }^{4}$ Princípio da evolução ou processo de divindade primordial na natureza, fonte de revolução, leis, convenção humana. Fonte: definição em Oxford Languages.
} 
não é isolado, estagnado, imutável. A constante desconstrução da noção do trabalho docente, na administração escolar a respeito do entendimento de educação, possibilita uma melhor compreensão das especificas problemáticas num contexto educacional coletivo. A ferramenta primordial ao processo de aprimoramento da prática de lecionar e formação da cidadania é, de fato, a filosofia. Portanto, afirma-se que o filosofar é um dos mais importantes conhecimentos humanos, da união entre os saberes teóricos e práticos. A ética e a política sendo ciências teóricas da práxis, cujos objetos dependem de intervenção humana, apropriam-se de seu mesmo sentido e finalidade. Enquanto a práxis é dependente da vontade racional no caráter do agente e, das condições concretas em que a situação é dada, a teoria da filosofia busca, em contextos e diversos modos, a interrogação, o alcance da compreensão na linguagem crítica, rigorosa, radical, fiel em descrever a natureza sobre realidades, do essencial, real ou irreal.

Filosofia é, portanto, a capacidade individual e, principalmente coletiva, do exercício dos direitos, deveres à cidadania, noção sociopolítica do espaço, da luta de classes, respeito às multiculturalidades étnicas e religiosas. Ser filosofante e agir como tal é, impedir as perdas cotidianas daquilo que nos é garantido, tomar para si ações como atos de coragem, participar ativamente enquanto cidadãs e cidadãos, da reestruturação em sociedade e, envolver-se nos debates sobre as especificidades das operações de questões políticas brasileiras. Portar-se em combate à desigualdade, discriminação, exclusão e no empenho, trabalho, para o acesso à educação, inserção, acolhimento pedagógico, permanência na escola, a institucionalização das ações afirmativas como cotas sendo, medidas emergenciais para a representação civil. Assim sendo, a filosofia envolve amor, compaixão, solidariedade, amparo e participação de sujeitos operantes ao coletivo, emparelhados ao sistema político, regidos por fatores sociais determinantes. A escola deve conduzir a sociedade à luz, isto é, não servir como papel alienador, sim de libertação, assim vale à religião, as tecnologias que envolvem as diversas redes sociais e outros instrumentos onde, ocasionalmente, persuadem à desorientação, insanidade, delírio e loucura social.

Especificamente, sobre os estudos e pesquisas da criança ou do processo de desenvolvimento infantil é recente na história, e, relacionar a colaboração da filosofia em sua essência como amparo à vida desde seu princípio, diferencia-se de sujeitos passivos a sujeitos questionadores da sociedade. A formação da criança advém do trabalho docente, junto ao papel da escola enquanto espaço de concepções, realizações, avaliações de projetos educativos, onde, requer a organização pedagógica baseada em fundamentos da filosofia, a fim de agregar valores e conhecimentos aos alunos/as. Para professores e professoras, assumir responsabilidades sem ansiar que esferas administrativas superiores tomem iniciativas, é um 
dos grandes desafios à alfabetização. Possibilitar no ensino, condições necessárias para levar adiante a formação continuada, considera-se o fortalecimento da relação escola e a especificidade da educação, o aprimoramento, engajamento dos saberes científicos sistematizados.

As vivencias das crianças nos processos educativos da escola, viabilizam rumos e direções para ações intencionais com sentido explícito, no compromisso pedagógico definido coletivamente. Ou seja, trata-se também, do papel político escolar, uma vez que a educação filosófica está ligada intimamente ao compromisso sociopolítico com interesses reais e coletivos da população, na formação cidadã para a sociedade. Na esfera pedagógica, reside a possibilidade de efetivação da intencionalidade da escola, a formação da cidadania participativa responsável, compromissada, crítica e criativa, para definir ações educativas e características necessárias para o cumprimento dos propósitos e intencionalidades do ofício docente. Dito isso, o autor Matthew Lipman afirma em seu livro de Filosofia para crianças, complementando ao que foi dito anteriormente que:

\begin{abstract}
Um programa confiável de habilidades de pensamento deveria fazer mais que capacitar as crianças a lidarem de modo efetivo com as tarefas cognitivas imediatas, tais como problemas a serem solucionados, ou decisões a serem tomadas. Deveria buscar consolidar as potencialidades cognitivas das crianças, de modo a prepará-las a um pensar mais efetivo no futuro. O objetivo de um programa de habilidades de pensamento não é transformar as crianças em filósofos, em tomadoras de decisões, mas ajudá-las a pensar mais, ajuda-las a terem mais consideração e serem mais razoáveis. As crianças que foram ajudadas a serem mais criteriosas não só tem um senso melhor de quando devem agir, mas também de quando não devem fazê-lo. Não só são mais discretas e ponderadas ao lidarem com os problemas que enfrentam como também se mostram capazes de decidir quando é apropriado adiar ou evitar tais problemas em vez de enfrentá-los diretamente. Assim, um dos objetivos do programa de habilidades de pensamento deveria ser o desenvolvimento do juízo, pois ele é o vínculo entre o pensamento e a ação. As crianças que refletem estão preparadas para emitir bons juízos e crianças capazes de realizar bons julgamentos, dificilmente agirão de maneira inadequada ou sem consideração. (LIPMAN, 2001, p. 35).
\end{abstract}

No universo infantil, os processos reflexivos, questionamentos, busca de alternativas viáveis compreende a criança como única, pensante e atuante no meio. A contínua construção da identidade propicia vivência democrática necessária à participação ao exercício da cidadania. É uma recíproca relação entre política e pedagógica.

Para a possibilidade de construção do pensamento filosófico, do exercício ao atoa de filosofar inconscientemente, e necessária a autonomia do/a sujeito/a junto à sua capacidade de delinear a própria identidade. Ou seja, o resgate do diálogo, o ofício docente na dinâmica 
interna da sala de aula, postura da administração central, são conjuntos de requisitos para a organização do serviço da mudança substancial da prática e remete, o significado de conteúdos científicos para as crianças, conforme cita Lipman:

\footnotetext{
Os significados não podem ser partilhados. Eles não podem ser dados ou transmitidos às crianças. Os significados precisam ser adquiridos: eles são capta e não dados. Temos que aprender como estabelecer as condições e oportunidades que capacitarão as crianças, com sua curiosidade natural e ansiedade por significados, a se apoderarem das pistas adequadas e, por si mesmas, imprimires significado às coisas. (LIPMAN, 2001, p. 32).
}

A mobilização de educadores/a, equipe escolar, funcionários/as, significa propiciar situações que permitam as crianças pensarem, operacionalizar o meio de forma pedagógica coerente, sobretudo, consciente. As lutas da escola é, portanto, a descentralização na busca da autonomia, qualidade efetiva do ensino.

Educação em seu sentido largo e amplo na perspectiva da sociedade capitalista, reflete em seu interior, determinações, contradições sociais. Abordagens filosóficas servem como organização de trabalho educacional que, fundamenta-se nos princípios democráticos, igualdade, oportunidades, manutenção da qualidade. A gestão escolar deve exigir clara compreensão das problemáticas postas na prática pedagógica, o rompimento entre pensamento/ação, teoria/realidade, a fim de possível auxílio no resgate e controle do trabalho de lecionar. Repensar a estrutura de poder da escola, bem como sua socialização, propicia participação coletiva, atenua o individualismo, anula da dependência de órgãos intermediários que elaboram políticas educacionais onde o papel da escola é a mera execução.

A ampla participação civil assegura transparência nas decisões da gestão democrática, fortalece pressões para serem legitimadas medidas fundamentais necessárias no campo escolar, garante controle sobre acordos estabelecidos, coopera para que questões sejam contempladas, onde em outras ocasiões não entrariam em cogitação.

Nesta acepção, é claro que compreender a gestão democrática escolar, não é fácil ser consolidada, já que propõe a participação crítica na construção de projetos pedagógicos. Quando se tem uma autonomia relativa e, liberdade só é experimentada em específicas situações, esta é uma articulação de limites, impossibilidades. A liberdade aos educadores/as, constrói-se na vivência coletiva interpessoal, ela deve ser pensada na relação entre 
administradores/as, docentes, funcionários/as, alunos/as, que então, assumem a parte da responsabilidade na construção do conhecimento e na relação destes com o contexto social.

A aplicação analítica dos/as membros da escola possibilitará a identificação das finalidades que devem ser reforçadas, quais as relegadas e, como elas poderão ser detalhadas em nível das áreas de diferentes disciplinas curriculares dos conteúdos programáticos sistematizados, e, o trabalho interdisciplinar continuado. Para efetivação de possíveis mudanças no ensino, a filosofia desempenha papeis fundamentais na criação de conceitos, a formação intelectual, o (re)inventar-se, como complementa o filósofo Ildeu Moreira Coêlho no livro Filosofia, Educação e Cidadania:

Em vez de ensinar, no sentido de trazer respostas acabadas para todas as questões e situações, ele pergunta, questiona, busca o sentido do real, cultiva a maiêutica, suscita no interlocutor o insaciável desejo de saber e o ajuda a trazer à luz as ideias, como um autêntico parteiro intelectual. Ao fazê-lo, cria conceitos, um saber vivo em contínuo processo de se fazer, institui o pensamento da existência humana. (COÊLHO, 2001, p. 19).

A estrutura organizacional da escola enfrenta problemas que afetam o processo do ensino -aprendizagem, de modo a favorecer a tomada de decisões realistas. As avaliações de baixos índices da qualidade do ensino expressa o questionamento dos pressupostos eu embasam a estrutura burocrática do sistema escolar, onde, inviabiliza-se a formação cidadã apta a criar e modificar a realidade social. Para cumprir as finalidades é necessário o rompimento com a atual forma de organização que regula o trabalho filosófico pedagógico, pela correspondência às regras fixadas, obediência as leis, diretrizes que embasam, fragmentam o controle hierárquico. Situar obstáculos, vislumbrar possibilidades, estabelecer relações, configuram novas formas de organização das estruturas administrativas e pedagógicas para a melhoria do trabalho nas instituições educativas, combinado a isso, o currículo é o elemento importante e constitutivo para o referencial teórico produtivo do/a professor/a, enquanto construção social do conhecimento, exerce o papel de sistematização dos meios para que a estruturação se efetive.

O processo da produção do conhecimento requer análise e compreensão curricular, uma vez que, os saberes escolares são dinâmicos e não apenas mera simplificação da aprendizagem científica adequadas à faixa etária e aos interesses de cada sujeito/a. Fatores consideráveis básicos, carecem de discussões e ações práticas, como de que o currículo não se trata de instrumento neutro, dispõe carga ideológica e, a escola necessita identificar e desvelar 
os componentes do conhecimento que a classe dominante utiliza para manutenção dos privilégios. Na literatura de Franz Kafka, A Metamorfose (2011), o personagem central, personifica-se na descrição de algo que se assemelha a uma barata, retratando os problemas sociais, conta narrativa literária onde, dedicado trabalhador caixeijo-viajante desperta no corpo de inseto, e, a inquietação naquele momento, era sobre o atraso no trabalho, não por sua condição animália atual. As metáforas utilizadas para aproximação ao cotidiano humano equiparam a posição de trabalhadores/as no enfrentamento das imposições sociais. $\mathrm{O}$ protagonista principal Samsa morre, seu círculo familiar se tranquiliza, afinal, só era tido como útil no momento que fornecia sustento à família:

Estava deitado sobre suas duras como couraça e, ao levantar um pouco a cabeça, viu seu ventre abaulado, marrom, dividido por nervuras arqueadas, no topo do qual a coberta, prestes a deslizar de vez, ainda mais se sustinha. Suas numerosas pernas, lastimavelmente finas em comparação com o volume do resto do corpo, tremulavam desamparadas diante seus olhos. (KAFKA, 2011, p. 227).

As referências diretas ao capitalismo no livro para literatura estética, a transfiguração do estado humano ao corpo de inseto é, de dura crítica sobre relações que estabelecemos com o mundo. Mesmo Gregor dispondo dos sentimentos e pensamentos, a reação do meio se dá como fria, traumática, principalmente no sentido da cegueira quanto aos cuidados da alma, dignidade, respeito próprio. A forma desumana interrompe os padrões fixos físicos, relacionando-se à ideia de que igualdade não faz suficiente ao alcance da paz social, é irrefutável para o Estado Democrático de Direito prover meios às noções individuais.

\section{Filosofia educativa, escola, vida infantil}

Na construção da identidade, personalidade da criança, a filosofia coloca-se na posição de intenções do fazer, da realização e sobretudo, do pensar. Os planos educacionais filosóficos devem supor rupturas com o ensino do presente, promessas futuras, tentativas de fender do estado confortável ao risco de percorrer o período de instabilidade e ir à busca de condições adequadas no âmbito das humanidades. O compromisso torna-se visível nos campos de possíveis ações para indivíduos que comprometem e visam mudanças. De fato, a importância em analisar e, compreender de maneira geral os mecanismos de força que o Estado advém sob o social na tentativa de controle da reprodução, manutenção das massas, 
torna-se instrumento fundamental para prática pedagógica. É notável que o sistema capitalista impulsiona, altera a qualidade de vida, bem-estar social, manutenção da classe burguesa, limitação do poder de enriquecimento populacional onde, a renda concentra-se em classes mais altas, como grandes corporações, empresários e políticos que detém da liberdade em detrimento do Estado. Evidentemente o pensamento filosófico estrutura-se pelas vivências individuais e, pelo ambiente, isto é, desenvolve-se na esfera política, onde cada sociedade apresenta, revela condições determinantes para existência humana:

Sempre houve um enorme debate sobre como a sociedade e o Estado, como se
relacionam, qual deveria subordinar o outro e qual encarnar os valores morais mais
elevados. Assim, ficamos acostumados a pensar que as fronteiras da sociedade e do
Estado são as mesmas ou, se não, poderiam (e deveriam) ser. [...] Vivemos em
Estados. Há uma sociedade sob cada Estado. Os Estados têm história e, portanto,
tradições. [...] Esta imagem da realidade social não era uma fantasia, tanto assim que
os teóricos colocados em perspectivas ideográficas e nomotéticas desempenhavam-
se com razoável desenvoltura, utilizando esses enfoques acerca da sociedade e do
Estado e alcançando alguns resultados plausíveis. O único problema era que, à
medida que o tempo corria, mais e mais " "anomalias" revelavam-se inexplicadas
nesse esquema de referência; e mais e mais lacunas (zonas de atividade humana não
pesquisadas) pareciam emergir. (WALLERSTEIN, 1991, p. 246 apud IANNI, 2001
p.238).

O processo da relação social com a política brasileira na atual conjuntura, revela o modelo neoliberal, caracterizado por elementos tecnicistas de ensino com conflituosos padrões de exclusão e discriminação generalizada. A atribuição que a filosofia ocasiona do ponto de vista do ser é o caminho à libertação, isto é, não falsa sensação do 'ser livre', sobretudo, em seu significado mais profundo, da busca na percepção e assimilação dos conceitos presentes na sociedade, no enfrentamento aos medos e lutas diárias. No pensamento filosófico 'conhece-te a ti mesmo' representa a introspecção do 'eu', origina-se do ensinamento e sabedoria individual ao coletivo, isto é, a compreensão de si não é óbvia, inicia-se do questionamento das ações próprias e falas e há, por consequência, efeito no meio.

A análise sobre os défices de uma sociedade fechada e da transição passa-se, ao contexto atual propriamente dito, no qual pensamento pedagógico é denominado pelo período de transição que exige flexibilidade e a rapidez na formação, transformação da educação. A ideologia dominante constitui e administra o sistema, lucros, propriedades privadas de capital, conquista de espaços determinantes nas formações sociais, como a própria escola e a mídia colaboram para a hegemonia capitalista. A polícia e órgãos de controle de segurança, por sua vez, cerca a sociedade com poder da violência, protegida pelo Estado, a população em 
circunstâncias de constante ameaça amolda-se, e ajusta-se como convém. A constante guerra às drogas em grandes metrópoles brasileiras, apontam a ineficiência do governo em ações de políticas públicas em comunidades periféricas:

É precisamente devido ao fato de que elites estatais, convertidas à nova ideologia dominante do mercado todo-poderoso, irradiada nos Estados Unidos, reduzem ou abandonam as prerrogativas do Estado nos assuntos socioeconômicos que elas devem, de todas as formas, aumentar e reforçar sua missão nos assuntos de 'segurança' - após terem-na reduzido abruptamente à sua única dimensão criminal e, além disso, fazer a assepsia do crime da classe baixa nas ruas, em vez de enquadrar as infrações da classe alta nas grandes corporações. (WACQUANT, 2007, p. 203).

Soma-se a isso, as questões de insuficiência e escassez de programas socioculturais a nação, a arte como mecanismo de expressão e denúncia sofre transgressão na tentativa do autoritarismo político, em silenciar, censurar, manifestações contrárias aos interesses da elite. A filosofia, por sua vez, caminha, num contrário caminho à liberdade, na percepção liberal, empreendedores de grandes investimentos, ou pequeno grupo de empresários controlam o circuito financeiro do mercado, sendo que os interesses públicos regressam à subordinação do setor privado. Logo, o pensamento filosófico individual para plena liberdade, livre de estereótipos, da ignorância, deve-se conceder num espaço de ação e luta pela vantagem e benefício coletivo. Agir filosoficamente em acordo com a desambição, no lugar da indiferença, a resistência, vigor, no enfrentamento de uma justa sociedade, no espaço de privilégios, envolver o diálogo para relevantes causas. Sendo assim: "O liberalismo é um dos grandes fatos do século XIX, século que ele domina por inteiro e, não apenas no período em que todos os movimentos alardeiam explicitamente a filosofia liberal." (RÉMOND, 1974, p. 25). A revolução Francesa e a revolução industrial expressam o marco do Antigo regime aos elementos variados do modelo dominante vigente. As revoluções, movimentos e guerras tiveram como inspiração o liberalismo, espalharam-se aos EUA, França, Inglaterra e na Europa, com índole e propaganda à liberdade. A população deparara-se com a insatisfação e inquietação, assentou-se a necessidade de representação política, e, ao que veio a ser o neoliberalismo, como organização social, promoveu a ditadura e impulsionou desigualdade. Outras problemáticas de uma sociedade antidialogal, está evidente no falho sistema prisional, onde a educação, escola, a vida escolar é limitada, cidadãos com perdas cotidianas de direitos, torna o estudo dispensável e a criminalidade, por sua vez, torna-se a possível escolha. 
isto é, indivíduos tentando obter o máximo de lucro pessoal enfrentando-se uns aos outros, em uma abstração chamada "mercado", seria suficiente para entender eficiência na extração e na alocação de valores na sociedade, ademais de justiça social e bem-estar geral. Esta concepção torna desnecessária a existência de algum poder, cuja responsabilidade consistiria em garantir a maximização da racionalidade e a felicidade coletiva. (SANTOS, 1978, p. 68).

Na constante situação de miséria, o mercado manifesta cada vez mais competitivo, no esmagamento da classe operária, a crise socioeconômica aproxima-se do colapso total. Combinado a isso, as inconstâncias de políticos no governo agravam o quadro da pobreza social A instabilidade ao adoecimento populacional mundial, historicamente, comprova a necessidade estatal na execução de garantias dos direitos e políticas eficazes ao suporte econômico e bem-estar para nação. É incontestável que o mercado atue sistematicamente como mecanismo reprodutor de injustiças sociais, tendo base material o processo colonizatório e, a escravização, comprova no meio à divisão/separação das condições de trabalhos pré-determinadas pela hegemonia.

A relação hierárquica produzida culturalmente no mundo estruturalmente racializado atua nos vínculos entre pessoas e 'coisas', desse modo, igualdade/liberdade são determinações aparentes ao falseamento da realidade. A força de trabalho como mercadoria atrela-se à experiência de naturalização concreta do desequilíbrio na forma política atuante para desumanização, constituição do racismo estrutural. Evidentemente, o desfecho e as explicações futuras sobre a Covid-19 serão saberes úteis à humanidade, tanto no sentido de resultados científicos, como do entendimento da dinâmica comportamental sociopolítica.

As incertezas que a crise viral ocasionou, coexiste com as rearticulações ao capitalismo onde, dificuldades emergenciais patenteia-se nas classes desfavorecidas das condições primárias à vida: saneamento básico, sustento alimentício, acesso as unidades gratuitas- de proteção/acolhimento/suporte para saúde aos cidadãos e cidadãs. Outras garantias de direitos ditas em leis pela Constituição Brasileira (1988), preservam a segurança do povo, protegem os/as habitantes das possíveis vulneráveis situações ameaçadoras ao contágio/surto do Sars-CoV-2. O papel atribuído aos governantes em estabelecer harmonia e resguardo a união do Brasil, apresenta falhas, irregularidades e injustiças na efetivação de ações, condutas democráticas:

A economia política burguesa, de acordo com Marx, universaliza as relações de produção quando analisa a produção abstraindo suas determinações sociais específicas. Isso não quer dizer que a "base" econômica se reflita em certas instituições "superestruturais" e por elas seja mantida, mas que a base produtiva em si existe sob o aspecto de formas políticas, sociais e jurídicas - em particular, formas de propriedade de dominação. (WOOD, 2003, p. 29). 
Enquanto a sociedade brasileira se vê alheia aos seus direitos, ricos e militares obtém o auxílio emergencial através da plataforma digital desenvolvida pelo governo na instabilidade da pandemia, a justificativa não é a falha no sistema, e sim a autorização e compactação com a má distribuição da renda no país. A crise de valores e temas geralmente vinculados à política voltam à tona quando, eleitores e eleitoras, percebem e sentem-se enganados pelo discurso da anticorrupção:

O Estado Liberal não surgiu na história por puro acaso, certamente, mas também não é a consequência de uma necessidade lógica, silogística ou dialética, conforme se queira, a justificar as teorias naturalistas-objetivistas da aventura humana. Tal como todas as demais instituições políticas e sociais significativas, o Estado liberal foi o provisório resultado do choque entre interesses, ideias, projetos e ações geradas por novas e imprevistas relações sociais e econômicas. (SANTOS, 1978, p. 108).

O desmatamento desenfreado assusta e ameaça os biomas, fauna e flora do país. Atividades ilegais como o garimpo têm destruído a floresta amazônica de forma cruel, e o tráfico de animais, são problemáticas presentes no meio clandestino do Brasil. Para parte considerável da população não possui, saneamento básico, serviços de água tratada, coleta e tratamento dos esgotos, função do Estado, questão de saúde pública é revoltante. A privatização da água é questionada e colada em pauta nas discussões políticas, garantem mudanças e melhorias, assim como fizeram para a Reforma da Previdência, ou seja, a população já pagava, financiava ao Estado dispor de digna aposentadoria, agora, mais tempo contribuindo e pagando mais em juros e impostos, sem gozar do que lhes é direito, saúde, educação e bem-estar social. Dito isso temos:

[...] expandir o Estado penal lhes permite, em primeiro lugar, abafar e conter as desordens urbanas geradas nas camadas inferiores da estrutura social pela simultânea desregulamentação do mercado de trabalho e decomposição da rede de herança social. Também permite que os eleitos para cargos majoritários contenham seu déficit de legitimidade política com a confirmação da autoridade estatal nessa limitada área de ação, em um momento no qual têm pouco a oferecer a seus eleitores. (WACQUANT, 2007, p. 203).

A índole nazifascista, conservadora deve ser desmascarada em suas diversas facetas onde desenvolve-se, e combatida veementemente, o fanatismo distancia o pensamento da lógica, a cultura social molda-se pela violência e ódio, e, passa-se a conviver com o inacreditável. O golpe político efetiva-se, a importância da educação cidadã política social fica ainda mais evidente. O poder dos veículos de comunicação opera como artificio 
fundamental para campanha presidencial, o alastramento e propagação de notícias falsas provoca cooptação grande parte da população a compor escolha de uma frustrada representação política.

A liberdade está sofrendo contínuos atentados, o Estado de direitos extinto/ameaçado, o jogo da perseguição política vulgariza o lado doentio do governo brasileiro. As tentativas de silenciamento da nação civil reforça necessidade da quebra de tabus e paradigmas, o movimento-ação social pela dialética a favor da liberdade individual, neste processo:

[...], três rupturas analíticas mostraram-se indispensáveis, tanto para diagnosticar a
invenção de um novo governo de insegurança social, que combina o trabalho social
gerencial com o regime prisional punitivo, quanto para explicar a virada da política
punitiva. A primeira delas consiste em romper com o círculo vicioso do crime e
castigo, que continua a representar uma camisa de força nos debates acadêmicos e
políticos sobre o encarceramento, mesmo quando o divórcio desse casal familiar
cresce de forma cada vez mais descarada. A segunda ruptura requer que se volte a
relacionar bem-estar social com políticas penais, uma vez eu essas duas linhas de
ação governamental para com os pobres tendem a ser formadas pela mesma filosofia
behaviorista, que se vale da discussão, da vigilância do estigma e de sanções
gradativas para modificar a conduta. O bem-estar social renovado como trabalho
social e a prisão despida de sua pretensão reabilitadora formam agora uma única
rede organizacional, lançada sobre a mesma clientela atolada nas fissuras e
trincheiras da metrópole dualizadora. Eles trabalham em conjunto para invisibilizar
populações problemáticas, obrigando-as a sair da lista de ajuda pública, por um lado,
e mantendo-as atrás das grades, por outro e, no longo prazo, empurrando-as para os
setores periféricos do florescente mercado do trabalho secundário. A terceira ruptura
envolve a superação da costumeira oposição entre as abordagens de Karl Marx e
Emile Durkheim, de modo a levar em consideração e manter coesas as funções
instrumentais e expressivas do aparato penal. (WACQUANT, 2012, p. 13-14).

A resposta violenta do Estado a população, o debate e tentativa política para a redução da maioridade penal é preocupante, onde o sistema carcerário representa um ciclo vicioso e discriminatório, a educação parece cada vez mais distanciar-se de prioridades governamentais. Representantes políticos limitam-se como meras figuras midiáticas, de falsas promessas, os desdobramentos da guerra ao tráfico evidenciam a ineficácia e, fraqueza do Estado para garantia do bem-estar social:

Para Marx, a ideologia é uma forma de falsa consciência, correspondendo a interesses de classe: mais precisamente, ela designa o conjunto de ideias especulativas e ilusórias (socialmente determinadas) que os homens formam sobre a realidade, através da moral, da religião, da metafísica, dos sistemas filosóficos, das doutrinas políticas e econômicas etc. (LOWY, 1985, p. 10).

Os mecanismos e engrenagens da economia operam de modo ao esgotamento de recursos naturais, rápido avanço do aquecimento global, rede, materiais de consumo insustentáveis. As energias limpas e renováveis são existentes, entretanto, inacessíveis a população, não apenas pelo alto valor, pelo desinteresse de governantes de ofertar meios de 
manutenção da sustentabilidade e reciclagem. Grandes manufaturas, caça ao petróleo fizeram do mercado uma máquina de destruição em massa do meio ambiente, o agronegócio, por sua vez, contribui e impulsiona o declínio de políticas eficientes. O descumprimento de grandes latifundiários na devastação e degradação de terras brasileiras, sobretudo em 'áreas de reserva ambiental' é grave. Evidente que o processo de reflorestamento é complexo e demorado, o eucalipto e árvores de vegetações não-nativas em determinadas áreas, significa a perca total da originalidade, história, vida selvagem. Rios, oceanos poluídos, esgotos à céu aberto, denunciam a negligência do Estado na conservação do espaço social que estamos inseridos/as. O confronto dos interesses sociais, como coleta seletiva do lixo, tratamento de água são de relevância pública. Sacolas plásticas sustentáveis, renováveis deveriam ser a realidade e prioridade na nova perspectiva de vida com os avanços científicos e tecnológicos. A reforma agrária torna-se precisa, na tentativa da (re)distribuição latifundiária.

O Estado é a instituição criada pela necessidade histórica e política da classe dominante de uma nação, em que se definem poderes que podem ser exercidos por um governo em dado espaço e tempo. Modernamente, esses poderes são exercidos em nome da lei, para essencialmente manter a ordem - política, social e econômica. É uma instituição porque é reconhecido como legítimo pelos que o aceitam ou impõe: é criada por acordo histórico em face de representar um momento da história de um povo que se constitui nação e se organiza politicamente, assumindo direitos e deveres, em certas condições relativas de escolha, é político porque se trata de um acordo cercado pelas contingências das disputas de poder, em que classes e segmentos de classe lutam por domínio e hegemonia, uma dominação modernamente exercida com a lei, tendo em vista manter o estabelecido. Eventualmente, em condições revolucionárias, o Estado é usado para transformar a realidade, promover mudanças radicais ou moderadas em dada sociedade, (GURGEL, 2007, p. 7)

Num contexto dos movimentos negacionistas, anti-vacinas, verifica-se, como a sociedade comporta, revida, no cotidiano da cultura de violência, o silenciamento, tentativa do desmanche para áreas da linguagem ao espaço da fala pela filosofia, sociologia, das ciências humanas, faz contrário caminho à educação libertadora, em manifestação, ações com cunho violento, são marcas evidentes do social em desequilíbrio:

As violências exercidas pelo Estado no âmbito do Estado-nação, podem ser assim identificadas: violência exercida por membros das polícias, civis e militares, federais, estaduais ou municipais; a violência programada nos programas de colonização e assentamento; as violências do Estado contra os direitos humanos (direitos civis, políticos, sociais e direitos de quarta geração). Porém, aqui devem estar os efeitos violentos da crise do Estado-providência (crise da habitação, da saúde, da educação e da segurança) e os efeitos sociais de políticas econômicas de ajuste estrutural sobre o emprego e a renda. (TAVARES DOS SANTOS, 2007, p.75). 
Violações de direitos humanos pela violência policial, patenteia a importância da dedicação ao envolvimento das ações/militâncias política para sugestões, tentativas, de transformações estruturais à segurança pública; nas melhorias dos espaços, envolvem atuações práticas ao movimento cotidiano por justiça, cidadania. Diferentes áreas pela integração de políticas preventivas com importantes papeis na luta contra homofobia, racismo, violência, e, defesa ao meio ambiente, as crianças/jovens/adolescentes/adultos/idosos possuem como propósito, acionar propostas às reformas na arquitetura institucional brasileira para exercício de redução aos homicídios pela opressão autoritária.

Os pequenos insuficientes avanços constitucionais sobre transparência e progressos incrementais, não demonstram eficazes à área de segurança social. O poder da polícia acompanha tensões, disfuncionalidades, arbitrariedades, que não adotam medidas de pacificação ou reparação dos danos. Para ampla mudança estrutural, complexos desafios são realidade na tentativa do rompimento aos modelos contrários de policiamento civil/militar. Alarmantes dados referentes a população carcerária do Brasil, denuncia a ineficácia política de guerra às drogas que o Estado estabelece.

A seletividade hierárquica de policiamento, define alvos e focos criminosos as ações repressivas investigatórias. As negligências das organizações ao supervisionamento/fiscalização policial, age e articula como posições institucionais discriminatórias que normatizam rotinas, dinâmicas reprodutivas ineficientes no enfretamento de crimes. O respeito aos direitos humanos como parte da corrente progressista no caminho à justiça criminal deve agir, pelas polícias, compativelmente à racionalidade integrada às práticas diárias em benefício comunitário, desarticulando brutalidades, abuso de autoridade e violência.

A implementação de políticas para segurança pública no Brasil, são marcos legais institucionais as modificações estruturais do caráter civil e militar, na cooperação da polícia como agente/ofício responsável a manutenção, revisão do meio sociocultural. Evidentemente, a transição é lenta e gradual, os movimentos sociais atuam como garantias do estado democrático de direito na vida das pessoas. O empenho em oposição aos atos ilegítimos, destrutivos, a busca por alternativas restaurativas, colabora ao comprometimento das reformas pelo debate, participação, reinvindicações sociais objetivas, democráticas e, organizada.

$\mathrm{Na}$ perspectiva do presidente e do governo, o desaparecimento ao ofício docente, assim como a filosofia, coloca-as em posições de 'subprofissões', e, dissipa-se para 
concepção social. Os transtornos ocasionam aumento da conivência com o nosso processo de precarização. A ação individual deve ser, portanto, no sentido da valorização da prática de ensino e ao exercício para pesquisas. A ideia generalizada da lógica destrutiva do ato de lecionar é ofuscada pela natureza, significado de ser educador e educadora no Brasil, a efetiva salvaguarda ao caos social instalado. Sendo assim, no processo de transformação, situam-se desafios e disfunções da sociedade alienada e violenta:

É necessário sublinhar que houve uma mudança quantitativa e qualitativa com relação à violência. A violência do Estado contra os de baixo não tem mais o senil de papel de impedir que as formas mais razoáveis de distribuição da riqueza na modernidade em expansão se efetivem, mas de conter o processo de dissolução de uma modernidade em fim de linha. E a violência da própria sociedade é uma nítida manifestação de seu processo de dissolução (MENEGAT, 2013, p. 14).

É indubitável, existe um caminho longo para entender o escrito clássico de Smith e, o pensamento dos neoliberalistas. Sobretudo, em A Riqueza das Nações (1996), o laissez faire e o laissez passer $^{5}$ - o deixa passar, o deixa fazer - de Adam Smith, está longe de ser entendido em sua originalidade. A famosa mão invisível da atualidade se configura muito mais como uma mão que rouba, explora, domina o cenário econômico. Essa compreensão foge e muito do que aquilo que Smith revelou, conforme explica Fritsch:

\begin{abstract}
A concentração da violência policial sobre as populações pobres e sobre os seus locais de moradia não é um ato isolado e de significados. Desde que as favelas surgiram, o Estado incumbiu aos agentes da lei - os policiais - a tarefa de reprimir as populações, seja derrubando os barracos, nas remoções; seja, na busca de criminosos, e mais tarde, já na década de 1980, na caça aos traficantes e às drogas. Portanto, a função da polícia para essa parcela pobre e habitante "ilegal" da cidade, não é de garantidora dos direitos da população, mas de repressora, em nome do Estado. (FERRAZ, 2004, p.18).
\end{abstract}

Por sua via, o neoliberalismo incentiva o aumento da produtividade e indica a redução de preços e salários como forma de melhoria da economia local/global, tal sistema aprofunda desigualdades tendo caráter do individualismo, tornando o capital como o recurso e subsistência da classe operária à burguesia.

\footnotetext{
${ }^{5}$ Expressão em língua francesa 'laissez faire, laissez aller, laissez passer', significa 'deixai fazer, deixai ir, deixai passar'. Fonte: disponível em educação.uol.com.br/disciplinas/historia/iluminismo-3-ilaissez-fairelaissez-passeri-e-o-despotismo-esclarecido. Acesso em 20/10/2021.
} 
A condenação de qualquer crime que conduza pessoas ao cárcere confronta inúmeros desafios. As prisões como aspecto inevitável à vida em social devem ser efetivadas reformas no sistema prisional onde, entende-se no sentido sensível aos direitos humanos a negação da determinação à pena de morte como meio punitivo. Compreender e atuar politicamente para ativismo antiprisional é, estabelecer noção ao significado dos danos ocasionados em quaisquer infrações para ambas as partes (vítima, infrator/a), por ínfimo que seja a criminalidade. Exigir políticas restaurativas para soluções de alternativas na redução do aprisionamento da população tende no sentido libertador, em combate persistente ao racismo estruturado, potencialmente problemático em sistemas sociais que operam o modelo econômico, sociopolítico capitalista.

O consumo e, a utilização midiática tende ao sensacionalismo criminal, programas televisivos disseminam imagens/vídeos de caráter violento, os discursos políticos para engrandecer-se, discutem possibilidade da criação das (mais), celas penitenciárias na cidade, escancara a cultura característica na banalização e construção do irracional diante o confinamento em massa da população, maiormente negros/as. Nosso ambiente imagético formam as considerações existentes normalizadas, naturais, e, sem ação crítica posicional, os processos aos questionamentos, oposições, parecem camuflar no contexto político brasileiro. O imediatismo na descriminalização do uso de drogas, ajusta-se em estratégias das justiças reparadoras, nas quais a prisão não é solução base ao êxito no alcance à democracia. A segregação negra e, supremacia branca, dominam os espaços de poder, o presente permanece sem respostas aos acontecimentos históricos, provas obstruídas ou apagadas calam vidas na perpetuação do preconceito, da indiferença.

As ideologias que governa(ra)m a escravidão são mecanicamente movidas ao mesmo princípio dos governos autoritários, isto é, o uso da força violenta no controle dos corpos e, manutenção das reproduções em detrimento aos interesses estatais. A interrupção no tratamento opressor do Estado se dá, sobretudo, na afirmação antirracista diante realidade vivida, reconhecer, adotar posturas críticas sobre agora, contorna, desenha, futuros das possibilidades em reformas institucionais onde, as formas violentas de execução ao castigo/disciplina que lese o individual, sejam modificadas na edificação da educação livre como responsabilidade pública ao exercício da cidadania para direitos, deveres.

As aparelhagens entre Estado/sociedade não definem diálogo, o terrorismo, os governos autoritários de extrema direita são marcos da história de destruição, sofrimento, a filosofia ilegítima age, comporta-se no interior individual do pensamento próprio ocasionando 
insanidade/loucura. Verifica-se, a ruptura ética, moral, pessoal de crianças, pessoas sequestradas para viver, atuar na realidade terrorista, é uma passagem perdida e perigosa de tantos indivíduos, certamente sem o poder -ou mínimo- da escolha, o governa declara-se como inimigo e, não como estrutura de amparo:

Dessa forma, o caráter autoritário e violento da polícia sobre as populações de baixa
renda e seus locais de moradia (favelas, morros, conjuntos habitacionais e posses)
são vistos como atos normais, por grande parte da sociedade, dos meios de
comunicação e dos agentes responsáveis pela segurança do Estado, reproduzindo o
discurso de que bandido e favelado são sinônimos. A "metáfora bélica" ganha
apoio de diferentes setores da sociedade e justifica todo tipo de violência.
(FERRAZ, 2007-2008, p. 200).

Pensar que o problema da polícia não se dá em razão da conjuntura política, onde, as circunstâncias não nos afetam, aponta a profunda negação da realidade, maiormente, da própria ignorância na plena significação:

\begin{abstract}
Vale dizer, a soberania do estado seria caracterizada pela marca eloquente e ostensiva da força, como nos disse Weber, numa passagem célebre, ao afirmar que o estado seria o único detentor legítimo da força. Porém ao perder parcela significativa de sua força para as corporações transnacionais e capitais financeiros, no contexto da globalização, o estado-nação procura reafirmar a sua força perdida pela exibição e a ritualização grotesca desta, pela construção do estado penal na regulação ostensiva da insegurança social. (WACQUANT, 2012, p.35).
\end{abstract}

A uso da força governamental pelas polícias, militares, órgãos públicos assenta lesão aos direitos humanos civis, também, corrompe sociedade. Instituições de poder do Estado, como escola, propaganda, religião, toleram, pactuam numa sistêmica 'mecânica violenta', fraudulenta, na tentativa da implementação das ideias do pensamento dominante hegemônico presente, filosofias liberais influenciam, contagia, aflige crianças, jovens, futuros adultos/as durantes gerações prosseguindo nações pela repetição histórica, caminhando no mesmo ciclo. Fragmento da canção 'o tempo não para' (1988), do grupo Cazuza, recita: “eu vejo o futuro repetir o passado, eu vejo um museu de grandes novidades', são narrativas pessoais da revolta política contextual injusta, em impotência humana de sereis mortais, fatais ao vulnerável, "disparo contra o sol, sou forte sou por acaso, minha metralhadora cheia de mágoas, eu sou um cara, cansado de correr na direção contrária', anuncia esperanças numa releitura daquilo que historicamente é velho apresenta como desanimador, corrosivo, pode ser viver sob domínio do Estado soberano e, no efeito das mídias sociodigitais interferindo toxicamente no comportamento humano. 


\section{O Estatuto da Criança e do Adolescente como marco legal constituinte fundamental ao exercício dos direitos infantis}

Analisar a importância do Código Civil de 2002, em concordância com Estatuto da Criança e do Adolescente, Lei $n^{\circ}$ 8.069/90, na ponderação dos princípios constitucionais que abordam, sem dúvida, o arbítrio da família como responsabilidade de atenção pública. Destacar os limites nas situações do poder familiar fundamenta condições específicas no cuidado, zelo, para ações legítimas beneficiando as execuções aos deveres conjuntos. A Constituição de 1988 respalda tutela constitucional da proteção, defesa dos direitos das crianças e, jovens, o conselho tutelar, casas de acolhimento objetivam construir os princípios da dignidade humana.

Pelas relações jurídicas faz-se, a existência do Estado, não o contrário, direito civil estende ao comunitário no dever efetivo das políticas públicas sobre vida, saúde, saneamentobásico, alimentação, educação, bem como, acesso aos esportes, lazer, convivência sociocultural. O contexto cotidiano infantil inclui equilíbrio físico/emocional, negligenciar garantias constitucionais ao bem-estar é privar sujeitos para desenvolvimento saudável. A ação estatal para declínio da taxa de evasão escolar, permanência na escola, deve proceder pelo Poder Público amparando, subsidiando defesas aos cidadãos e, cidadãs do infantojuvenil. As críticas aos dogmas sexistas, heteronormativistas, reformam tradicionais técnicas pedagógicas, a redefinição do conceito padrão de família classifica na compreensão legítima da palavra, na qual, não se limita pela figura de pai/mãe. A comunhão sociofamiliar é composta por características únicas que estabelecem diferentes relações entre ocupantes do mesmo espaço pessoal, estas são, casamentos em regime de união estável/namoro, separação/divórcio; famílias integradas por avós, 'mães solteiras', casais homoafetivos, compõem vínculos familiares genuínos, válidos legalmente. O regimento serve como guia nas mediações e, funções sociais, na estruturação dos hábitos naturais adeptos pela existência da organização de processos judiciais organizando, preservando, cautela legal no princípio para ampla defesa infantil a sobrevivência.

No sistema judicial acessível, transparente, as questões relativas às crianças asseguram-lhes em leis, o resgate da educação de direitos para justiça na infância. A pretensão na validação das ações civis está subordinada as decisões do Ministério Público, União, Associações legalmente constituídas no refúgio dos interesses. O movimento político popular une razão, a implementação de medidas socioeducativas eficientes, portanto, imprescindíveis 
nas determinações jurídicas justas. A defensoria pública incorpora atribuição primordial da operacionalização à isonomia, em tutelas políticas para integrantes sociais na infância/juventude. O ECA (Estatuto da criança e do Adolescente), justifica-se pela grave demanda das crianças em situações de risco e, exigências nas quais, subsistência é direito garantido pelo Estado, família.

Conferir proteção infantil determina ação do princípio amplo das defesas, no apoio permanente em instituições acolhedoras socioculturais, garantia ao direito na condição pacífica de condutas restaurativas para realidade social:

\begin{abstract}
É na competência do Ministério Público: zelar pelo efetivo respeito aos direitos e garantias legais asseguradas às Crianças e aos Adolescentes, promovendo medidas judiciais e extrajudiciais cabíveis (art. 201, inciso VIII, do ECA); promover Inquérito Civil e Ação Civil Pública para proteção dos interesses individuais, difusos ou coletivos, relativos à infância e adolescência (art. 201, inciso VII, do ECA); impetrar Mandado de Segurança, de Injunção e Habeas corpus em qualquer Juízo, Instância ou Tribunal, na defesa de interesses sociais e individuais indisponíveis afetos à criança e ao adolescente (art. 201, inciso IX, do ECA) e, entre inúmeras outras funções elencadas no Estatuto, inspecionar as Entidades Públicas e Particulares de Atendimento e os programas de que trata a lei, adotando de pronto as medidas administrativas ou judiciais necessárias à remoção de irregularidade porventura verificadas. (PEREIRA, 1996, p.452-453).
\end{abstract}

O Conselho Tutelar atuante como órgão autônomo, responsabiliza-se as relevâncias das causas infantis na competência jurisdicional do ofício profissional, em integração com Juiz/a da Infância e Juventude, Entidades de Atendimento as crianças/adolescentes, famílias, instituições escolares ou, outros espaços sociais a serviço das prescrições legais, é requerido para soberania popular ao movimento democrático participativo:

\footnotetext{
A utilização da via jurisdicional se faz necessária sempre que o Estado se omite quanto a alguma política social ou ação de abrangência individual contemplada pelo ECA. [...] a intervenção do Judiciário somente se impõe quando determinado direito social é negligenciado. Nessa hipótese, esse Poder está reconhecendo uma omissão inconstitucional por parte dos demais poderes. (MARCHESAN, 1998, p.99).
}

A transição histórica nas responsabilidades pedagógicas, destapam trágicas realidades naturalizadas das violações aos direitos humanos à criança. Mudanças da figura infantil representam consideração primordial em perceber jovens como pertencentes aos espaços públicos de forma livre nas comunidades, operantes na cidadania, portadores/a, das garantias às defesas sociopolíticas respaldadas em princípios constituintes de leis que 
executem, promovam integridade civil. A educação pela palmatória como castigo utilizado no Brasil Império, apresenta possível legalidade de práticas agressivas física/psicológica em escolas, o método utiliza-se por ordens autoritárias pelas quais, estabelece hierarquia rígida entre professora/o-aluno, operando didaticamente, na violência/medo para incentivo ao desenvolvimento da inteligência nas crianças. Com as mudanças dos papeis socioeducativos culturais, dinâmicas pragmáticas que se fundamentam no respeito ao livre pensamento humano presam pela pedagogia à justiça social. Qual motivação doentia da execução de tortura corporal no lugar da dialética consciente? Severo regime violento em orfanatos, casas de apoio, desmascara convivente Estado protetivo juvenil falho, onde os direitos são desconsiderados em nome daqueles que detém do capital, ricos, grandes empresários, resguardados pelo sistema judiciário criminal conduzido interesses burgueses. A sociedade indica fortemente nas dinâmicas comportamentais, as tendências ditatoriais autoritárias que se refletem nos cotidianos da polícia judiciária, também em atuações do Ministério Público, ou, poder judiciário. As relações sociais moldam os direitos humanos, somente no caminho ao movimento político reivindicatório se tem, possibilidades democráticas.

\section{Considerações Finais}

Admitir e, assumir as mazelas contidas na sociedade como problemáticas nãodistantes, sim, presentes no meio, atribui o trabalho para educação, um serviço de todo social, isto é, o obstáculo e diversidade alheia é também a luta minha, não determinada situação isolada e individual. Fazer dos espaços de atuação, luta política de responsabilidade cultural. Para a filosofia, a construção do pensamento, sobretudo para identidade, significa à prática pedagógica, oferecer ferramentas, técnicas científicas, ao desenvolvimento de habilidades. A escola deve ser como suporte à solidariedade. A política por sua vez, não pode estar em dívida com a sociedade, o acesso à saúde, educação, segurança pública é direito individual e, relaciona-se totalmente com a liberdade, felicidade coletiva.

O holocausto alemão sob domínio de Hitler comprova a obrigatoriedade da educação do pensamento livre para cidadania, exercida em favor de princípios dos direitos humanos, pelo voto democrático. O caso de Anne Frank, histórias no diário revelavam jovens sonhos, 
perdidos pela guerra, entre tantos outros crimes bárbaros da necropolítica ${ }^{6}$ que confessa e, se apresenta favorável, ao extermínio violento da nação. Nós falhamos enquanto civilidade humana quando os poderes das escolhas de cativar solidariedade, gentileza, simpatia, responsabilidade social é ofuscada pela violência e ódio instaurado em disfarçadas democracias. A filosofia da educação exerce papel unificador ao suscito reconhecimento de si, operando, compreendendo filosofar na pluralidade da assimilação dos conhecimentos às crianças.

A vida social cotidiana infantil em creches/escolas carece de projetos políticos pedagógicos para permanência, não-abandono da escola, incentivos federais/estaduais/municipais às redes de ensino que se distribuem à adequada merenda nutricional, transporte e deslocamento a instituição escolar, espaço pedagógico para o exercício de direito civil. O questionamento às contradições, necessariamente na área docente devem simbolizar atos políticos que, para favorecimento do meio, a construção da consciência em crianças dos conceitos filosóficos próprios de liberdade, do eu, vida, morte, alegria, tristeza, amor, dor, (...), se caracterizam como linguagem inicial fundamental ao desenvolvimento das formas de expressão, questionamentos, dúvidas da natureza humana. A ideia principal da filosofia em constante movimento se caracteriza na compreensão de que não é saber pronto, os contínuos esforços de leituras para o conhecimento de racionalidade física do mundo viabilizam posições políticas democrática. O sentido educativo filosófico às percepções, indagações infantis força o pensamento ao além do visível, empírico, do particular e, individual ao sentido amplo, questionável, da espécie.Certamente, a filosofia não trará respostas prontas para questões da angústia humana, ou mazelas universais. A natureza filosófica para busca da verdade própria, ocasiona manifestações particulares em quem lhe constata, atua logicamente e, na razão do ser, no campo investigativo/curioso natural.

A falta da clareza conceitual, intelectual das sociedades contemporâneas estabiliza e retrocede juridicamente os aspectos históricos básico de direito individual: acesso à informação. Na era digital onde desinformação tomou face do verdadeiro, o processo pela busca, averiguação científica, sobretudo, legitimar as confiáveis fontes midiáticas de pesquisas, na tentativa de conter fraudulentas eleições é vital.

\footnotetext{
${ }^{6}$ Achille Mbembe, filósofo, historiador, teórico político, professor universitário, escreveu em 2003 um ensaio, que posteriormente, virou livro, sobre os questionamentos dos limites da soberania quando o Estado escolhe quem deve viver e quem deve morrer. Ao negar a humanidade do outro qualquer, a violência torna-se praticável. Fonte: disponível em politize.com.br/necropolitica-o-que-e/. Acesso em 18/11/2020.
} 
O retorno do fascismo, os movimentos autoritários acarretado por sistemas neoliberais, representa quão é frágil conceito de inteligência artificial tendo total controle tecnológico para domínio/manipulação psicológica social. Os processos dos governos genocidas não alinham pela perspectiva que a vida humana pertence à terra, concebidos/concebidas originalmente pelo universo, no qual a existência da razão natural sucede na forma do exercício feito socialmente onde, agentes são livres ao deslocamento, caminhada, mobilidade espontânea, aos diferentes espaços geográficos, portando, e/migração das pessoas corresponde fator determinante à espécie, para identificação/manifestação da linguagem do ser com o meio que lhes são próprios por direito. Integrar reivindicações na busca em fender muros ao invés de construí-los, defende a democracia no combate às políticas de guerras, simpatiza por organizações favoráveis para falas comunitárias, sociais, manifesta contrarreações violentas ao alcance da solidariedade, afeto e, compartilhamento.

Talvez tenhamos criado muros diários que nos impeçam das possíveis aproximações, os tijolos deixam a parede cada vez mais alta, vendando visão daquilo que está à frente de nós ao ponto de separar as pessoas com polarização das ideias. A construção social pedagógica para cidadania deve orientar-se no cuidado das escolhas representativas políticas pelos interesses populares, atuante nas manutenções jurídica às cessões de garantias públicas.

\section{Bibliografia}

BRASIL. Constituição 1988. Constituição da República Federativa do Brasil. Brasília, DF: Senado Federal, 1988.

CHAUÍ, Marilena. O que é ideologia. 2a .ed. São Paulo: Brasiliense. Coleção primeiros passos, 2008. COÊLHO, Ildeu Moreira. 'Filosofia e educação' In: PEIXOTO, José Adão. (Org.). Filosofia, educação e cidadania. (Org.) Campinas: Alínea, 2001.

DINIS, Carlos Manuel dos Santos Jacinto. O que é a filosofia para crianças: programa de Matthew Lipman. Dissertação para obtenção do Grau de Mestre em Filosofia-Ética e Política. Outubro de 2011UNIVERSIDADE DA BEIRA INTERIOR - Artes e Letras. Covilhã, 2011.

FERRAZ, Joana D’Arc Fernandes. A Chacina de Vigário Geral: a violência como princípio. Rio de Janeiro, 2004.

FERRAZ, Joana D'Arc Fernandes. Do 'Mal Necessário' à 'Metáfora Bélica': A lógica dual do Estado Autoritário. Maracanan, vol. IV, n.4, Rio de Janeiro 2007, 2007-2008.

FRANK, Anne, 1929-1945. O diário de Anne Frank. Tradução de Alves Calado. 74ª . ed. Rio de Janeiro: Record, 2018. (p.83).

GURGEL, Cláudio. Administração Pública: bases para o estudo da administração pública. Niterói: UFF, 2007. 
HEIDEGGER, Martin. Que é filosofia? Ed. Livro ibero-americano. Rio de Janeiro, 1961.

IANNI, Octavio. Teorias da Globalização. $9^{a}$ edição. Rio de Janeiro: Civilização Brasileira, 2001.

KAFKA, Franz. Essencial Franz Kafka. Seleção, introdução e tradução de Modesto Carone. São Paulo: Penguin Classics - Companhia das letras, 2011.

LIMA, Caroliny Santos. Crianças Filosofando: uma proposta metodológica de ensino à luz de Matthew Lipman. Dissertação (Mestrado) do Programa de Pós-graduação em Gestão de Ensino da Educação Básica, Universidade Federal do Maranhão. São Luís, 2018.

LIPMAN, Matthew. O pensar na educação. Petrópolis, Rio de Janeiro: Vozes, 1995.

LIPMAN, M.; SHARP, A. M.; OSCANYAN, F. S. A filosofia na sala de aula. Tradução de Ana Luiza Fernandes Marcondes. São Paulo: Nova Alexandria, 2001.

LOWY, Michael. As aventuras de Karl Marx contra o Barão de Munchhausen marxismo e positivismo na sociologia do conhecimento. São Paulo: Cortez, 1998.

MANDEL, Ernest. Capitalismo tardio. São Paulo: Abril Cultural, 1982.

MENEGAT, Marildo. A crítica do valor bate a sua porta. In: Até o último homem: visões cariocas da administração armada da vida social. São Paulo: Boitempo, 2013.

MARCHESAN, Ana Maria Moreira. O princípio da prioridade absoluta aos direitos da criança e do adolescente e a discricionariedade administrativa. Revista dos Tribunais, V. 749, p. 82-103, mar. 1998.

PEREIRA, Tânia da Silva. Direitos da criança e do adolescente. Rio de Janeiro: Ed. Renovar, 1996.

RÉMOND, René. O século XIX, 1815-1915, introdução à história de nosso tempo. São Paulo: Cultrix, 1974.

SANTOS, Wanderley G. Ordem burguesa e Liberalismo Políticos. São Paulo: Duas Cidades, 1978, p.106.

TAVARES DOS SANTOS, José Vicente. As lutas sociais contra as violências, $\mathrm{N}^{\circ} 11$ Política e Sociedade, outubro de 2007.

WACQUANT, Loic. A ascensão do Estado penal nos EUA. In: BORDIEU, Pierre (Org.). De I'État social à I'État penal. Discursos sediciosos: crime, direito e sociedade, Rio de Janeiro: Revan, ano 7, n.11, 2002.

WACQUANT, Loic. Loic Wacquant e a questão penal no capitalismo neoliberal. BATISTA, Vera Malaguti (Org.). Rio de Janeiro: Revan, 2012.

WOOD, Ellen Meiksins. Democracia contra Capitalismo: A renovação do materialismo histórico. São Paulo: Boitempo, 2003. 